\title{
A DESCRIPTIVE ANALYSIS OF FACTORS CONTRIBUTING TO BUS DRIVERS' PERFORMANCES WHILE DRIVING: A CASE STUDY IN MALAYSIA
}

\author{
A.R. Ismail ${ }^{1}$, Siti Nur Atikah Abdullah ${ }^{2}$, A.A. Abdullah ${ }^{3}$ and B.M. Deros ${ }^{4}$ \\ ${ }^{1}$ Faculty of Creative Technology and Heritage, University Malaysia Kelantan, \\ Beg Berkunci No 01, 16300, Bachok Kelantan, Malaysia \\ Phone: +609-7797000 \\ Email: rasdan@umk.edu.my \\ ${ }^{2}$ Faculty of Engineering Technology, University Malaysia Pahang, \\ Lebuhraya Tun Razak, 26300 Gambang, Kuantan,Pahang, Malaysia \\ Email: abdullahsitinuratikah@gmail.com \\ ${ }^{3}$ Faculty of Mechanical Engineering, University Malaysia Pahang \\ 26600 Pekan, Pahang, Malaysia \\ Phone: +609-424-6353; Fax: +609-424-6345 \\ Email: adam@ump.edu.my \\ Phone: +609-549-2389; Fax: +609-549-2299 \\ ${ }^{4}$ Department of Mechanical and Materials Engineering, \\ Faculty of Engineering \& Built Environment, \\ Universiti Kebangsaan Malaysia, \\ 43600 UKM Bangi, Selangor, Malaysia \\ Phone: +603-8921-6117; Fax: +603-8925-9659 \\ Email: hjbaba@vlsi.eng.ukm.my
}

\begin{abstract}
This paper presents the factors contributing to a bus driver's performance. A bus driver's performance is important in ensuring the smoothness and safety of a journey. Descriptive survey research design was adopted for the study. The target population was the bus drivers along the east coast of Malaysia (Pahang, Terengganu and Kelantan). The data for the research was collected by using a questionnaire.
\end{abstract}

Keywords: Factors; performance; relative humidity; air velocity.

\section{INTRODUCTION}

Malaysia is one of the developing countries in Asia, with a population of 29,700,386 in 2015 [1]. This number shows that people need transportation to move from one place to another. It is, therefore, essential to provide an acceptable thermal environment in vehicles which will not disturb the passengers and ensure the optimal comfort and performance of the driver. Drivers are exposed to discomfort from more than one source simultaneously [2]. Environmental ergonomics, which is the application of knowledge of human characteristics to the designs of systems, is a branch of ergonomics and should be studied and practiced [3]. People in systems operate within an environment, and environmental ergonomics is concerned with how they interact with the environment from the perspective of ergonomics. Workplace conditions such as heat, humidity, indoor air quality, vibration and acoustics have significant relationships with 
the bus driver's satisfaction and performance [4]. Knowing the factors contributing to bus driver performance is very important as this provides a reference point in avoiding poor performance.

\section{LITERATURE REVIEW}

Air temperature can be defined as the surrounding air which determines the net heat flow between the human body and its environment[5]. A cooler environment is much more desirable compared to a warmer environment [6]. Usually, once a person feels uncomfortable with his or her surroundings, working to their maximum capability will feel unpleasant [7]. The best air temperature has been shown to be in the range of 21.6$23.6^{\circ} \mathrm{C}$ [8]. Air velocity is the speed of moving air in our surroundings. Air velocity controls the heat convection coefficients, which in turn can manipulate the rate of heat transfer without any change in air temperature. Air velocities inside vehicular compartments tend to be low, ranging from 0.1 to $0.4 \mathrm{~m} / \mathrm{s}$ [9]. Relative humidity can be defined as the volume of moisture in the air [5]. The thermal comfort zone for relative humidity is between $42-54 \%$ [8]. Whole body vibration is the frequency transfer to the whole body while seated in a moving vehicle [10]. The higher a person's exposure to whole body vibration (WBV), the poorer is their performance due to exposure to lower back pain (LBP) symptoms preventing them from focusing to their highest level [10, 11]. Air temperature, air velocity, relative humidity and whole body vibration exposure are factors for investigation as they affect a bus driver's performance [12, 13].

\section{METHODOLOGY}

\section{Population/Sample Size}

The population in this study was taken from among bus drivers in Malaysia. According to Persatuan Pemandu Bus Semenanjung Malaysia, the population of Malaysian bus drivers is approximately 800. This includes all the drivers of different buses such as express buses, tourist buses and others. However, in this study, the focus is on Kuantan bus drivers only with a sample size of approximately 260 drivers. When the population is 800 , the sample size should be 260 [14].

\section{Instrumentation}

The type of survey used in this study is in questionnaire form. The questionnaire has been created from many resources related to this study and is adapted for the preferences in this research from a study on thermal comfort by the Malaysian Automotive Industry [6] and a study of thermal comfort in outdoor and semi-outdoor environments in subtropical Sydney, Australia [15], and combines models of thermal comfort and air quality on buses in Hong Kong [16]. Every major item has been prepared using a 5-point Likert scale in the form of (1) strongly disagree, (2) disagree, [17] not sure, (4) agree, and (5) strongly agree. Determination of the 5-point Likert scale is common in social science research [18]. Table 1 shows the questions in the survey. 
Table 1. The questions in the surveys.

\begin{tabular}{lcl}
\hline Items & Question & Statements \\
\hline Air temperature & 1 & Does the temperature in the bus affect you? \\
Relative humidity & 2 & $\begin{array}{l}\text { Do you think productivity is affected by temperature? } \\
\end{array}$ \\
3 & $\begin{array}{l}\text { Does the humidity in the bus affect you? } \\
\text { Do you feel uncomfortable in your work due to } \\
\text { humidity? }\end{array}$ \\
Air velocity & 5 & $\begin{array}{l}\text { Do you think humidity affects productivity? } \\
\text { Does air movement affect you? }\end{array}$ \\
& 7 & $\begin{array}{l}\text { Do you feel disturbed by air movement in the bus? } \\
\text { Do you think the air movement in the bus should be } \\
\text { improved? }\end{array}$ \\
& 9 & $\begin{array}{l}\text { Do you agree that the productivity is affected by air } \\
\text { movement? }\end{array}$ \\
Vibration & 10 & How do you feel about the vibration level in the bus? \\
\hline
\end{tabular}

\section{Data Collection}

Data collection is a key tool in the overall performance measurement process. As for the data collection technique in this research, all the data were obtained by distributing questionnaires and the process of distributing and responding was fully administered, in person to ensure the quality of the responses and the data. The questionnaires were distributed and returned by the respondents on completion. The questionnaires were distributed to all bus drivers around Kelantan, Terengganu and Pahang. Three hundred questionnaires were distributed but only 212 fully completed questionnaires were selected. Another method of gathering data is an interview which provides a unique opportunity to uncover rich and complex information from an individual. While waiting for the respondent to finish answering all the items in the questionnaire, they were interviewed

\section{RESULTS AND DISCUSSION}

\section{Respondents' Profiles}

The respondents in this research were $100 \%$ male. Table 2 shows that no women respondents were recorded. With regard to age, $13.2 \%$ were in the range $21-30,30.2 \%$ in the range $31-40,14.6 \%$ in the range 51-60 and only $1.9 \%$ in the range $61-70$. The majority of respondents $(40.1 \%)$ were in the age range 41-50. On the question regarding average working hours per day, $60.8 \%$ said that they work 11-15 hours, $25 \%$ chose $6-10$ hours, $2.4 \% 0-5$ hours, $9.9 \% 16-20$ hours and $1.9 \% 21-25$ hours.

\section{Air Temperature}

For the first question (see Table 1), $0.5 \%$ totally agreed with the statement, $20.8 \%$ agreed, $43.4 \%$ were neutral, $3.8 \%$ disagreed and $31.6 \%$ totally disagreed. For the second question, $19.8 \%$ totally agreed, $55.7 \%$ agreed, $6.1 \%$ were neutral, $16 \%$ disagreed and $1.9 \%$ totally disagreed with the statement. Figure 1 shows the frequency analysis (\%). 
Table 2. Respondents' profiles

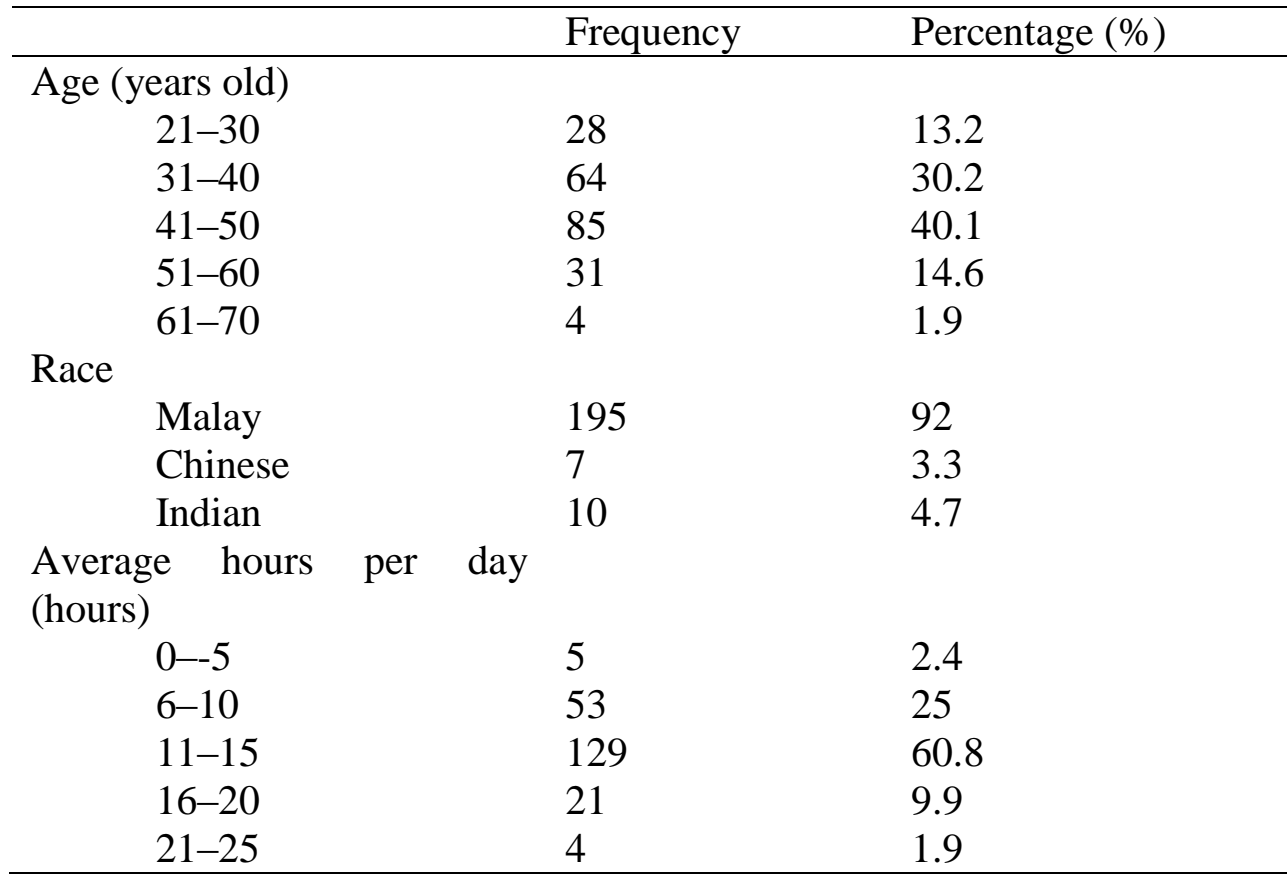

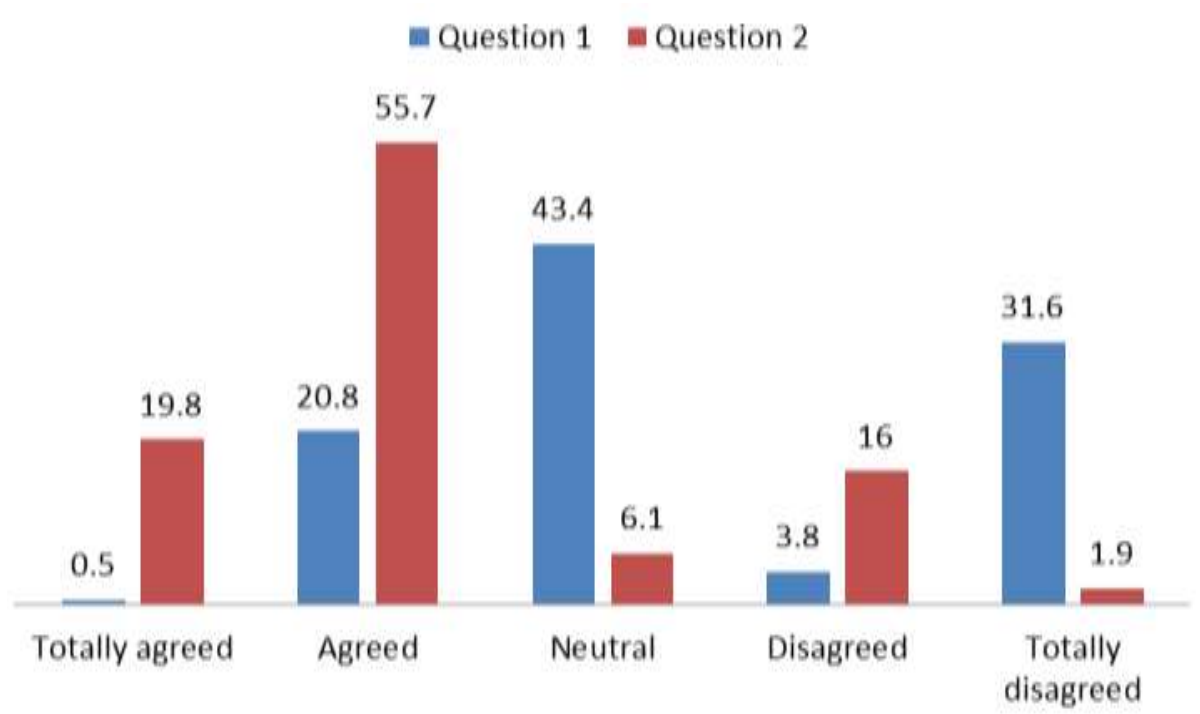

Figure 1. Frequency analysis for Questions 1 and 2.

The effects of the cold on human performance are often ignored and can be very significant [3]. The effects of the cold on manual performance can be attributed to a physiological reaction to the cold. The main effects from the cold could be slower speed, due to stiffening of the joints and slow muscular reactions, numbness and a loss in strength. These reactions cause deterioration in manual dexterity and hence in performance for many manual tasks. The unpleasant sensations of being too hot or too cold (thermal discomfort) can distract people from their work and disturb their wellbeing $[19,20]$. This may lead to reduced concentration and decreased motivation to work. The consequence of such a state is usually reduced productivity. Based on these results, we can conclude that cooler air surroundings may lead to better performance. 


\section{Relative Humidity}

For the third question, $6.1 \%$ totally agreed with the statement, $33 \%$ agreed, $12.7 \%$ were neutral, $44.3 \%$ disagreed and $3.8 \%$ totally disagreed. For the fourth question, $8.5 \%$ totally agreed with the statement, $31.1 \%$ agreed, $11.8 \%$ were neutral, $46.7 \%$ disagreed and $1.9 \%$ totally disagreed. For the fifth question, $9.9 \%$ totally agreed with the statement, $52.8 \%$ agreed, $12.3 \%$ were neutral, $21.2 \%$ disagreed and $3.8 \%$ totally disagreed. Figure 2 shows the frequency analysis for Questions 3 to 5.

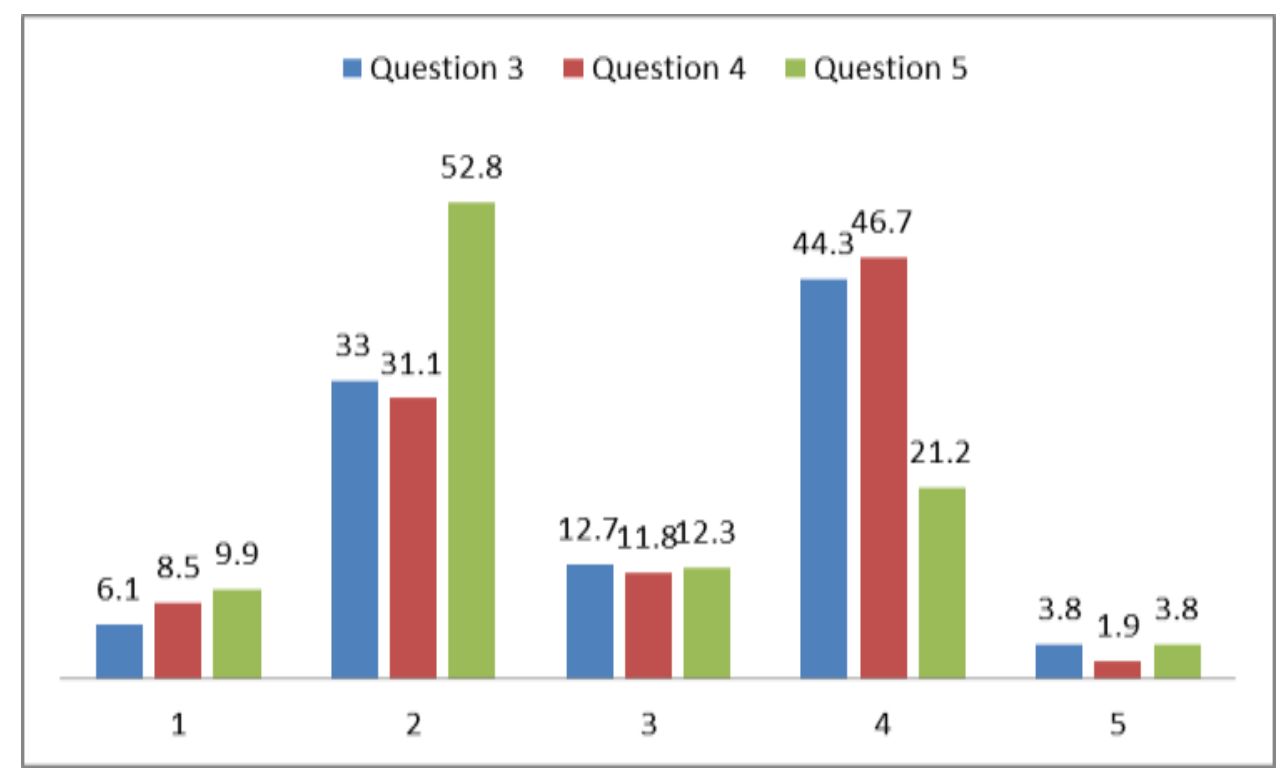

Figure 2. Frequency analysis for Questions 3, 4 and 5.

For thermal comfort, the majority of the respondents (49\%) chose relative humidity in a neutral condition in three locations, primary and secondary schools, and in public waiting areas in health clinics in Johor Bharu [21]. The results also show that a relationship exists between production rate and relative humidity [6]. It is directly proportional in that a higher value of relative humidity contributes to lower productivity. Based on the result, relative humidity does affect driving performance [22].

\section{Air Velocity}

As to frequency, $2.8 \%$ totally agreed with the sixth question, while $33 \%$ agreed, $10.4 \%$ were neutral, $49.5 \%$ disagreed and $4.2 \%$ totally disagreed. For the seventh question, $2.4 \%$ totally agreed, $30.7 \%$ agreed, $9.9 \%$ were neutral, $51.4 \%$ disagreed and $5.7 \%$ totally disagreed. For the eighth questions, $8.5 \%$ totally agreed, $31.6 \%$ agreed, $19.8 \%$ were neutral, $36.3 \%$ disagreed and $3.8 \%$ totally disagreed, With regard to the ninth question, $14.2 \%$ totally agreed, $54.2 \%$ agreed, $7.1 \%$ were neutral, $20.3 \%$ disagreed and $4.2 \%$ totally disagreed. Figure 3 shows the frequency analysis for Questions 6 to 9. This means that the air velocity in the bus did not disturb the bus drivers [23]. In his findings, $80 \%$ of the subjects felt satisfied that it was not draughty and they were not disturbed if the air velocity was not greater than approximately 0.9 $\mathrm{m} / \mathrm{s}$. It can be concluded that the air velocity in the bus is probably less than $0.9 \mathrm{~m} / \mathrm{s}$. 


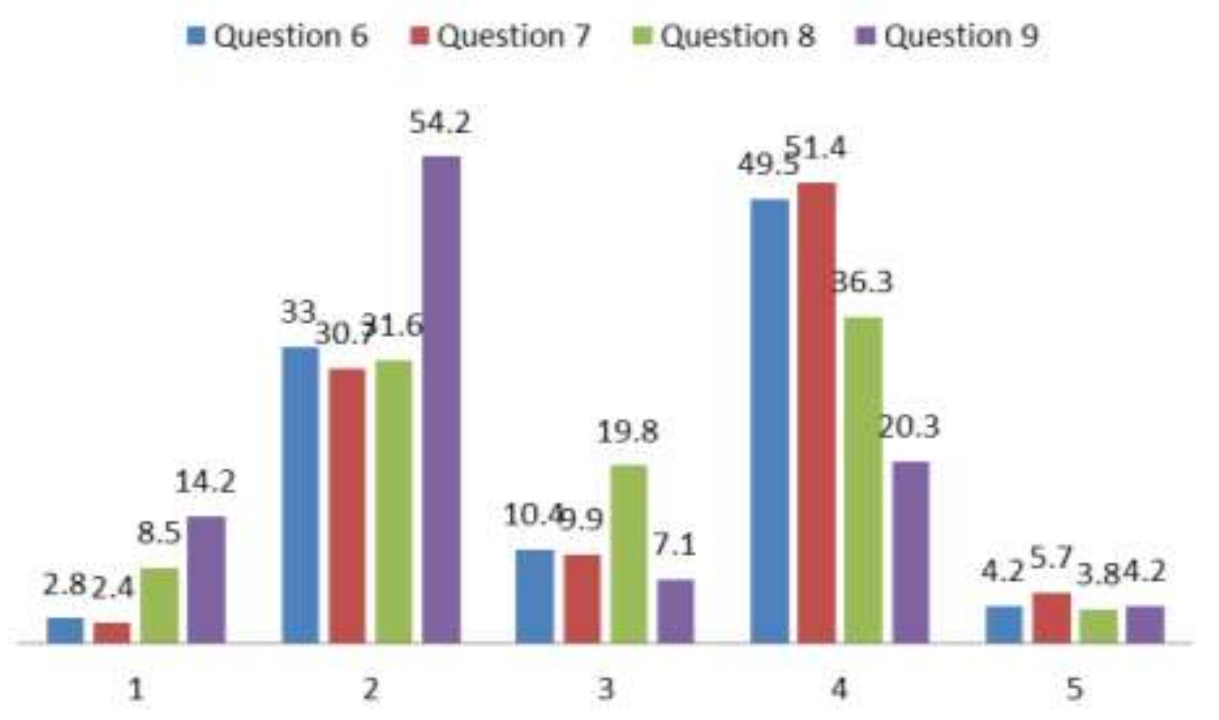

Figure 3. Frequency analysis for Questions 6, 7, 8 and 9.

\section{Vibration}

For the tenth question, $8.5 \%$ said the vibrations were very low, $55.2 \%$ reported low, $5.7 \%$ were not sure, $29.7 \%$ said the vibrations were high and $0.9 \%$ said the vibrations were very high. The level of vibration was acceptable to $79.7 \%$ of drivers and unacceptable to $20.3 \%$. According to $45.8 \%$, the source of the vibration was from the engine and according to $54.2 \%$ the source was the road conditions. Figure 4 shows the frequency analysis for Question 10.

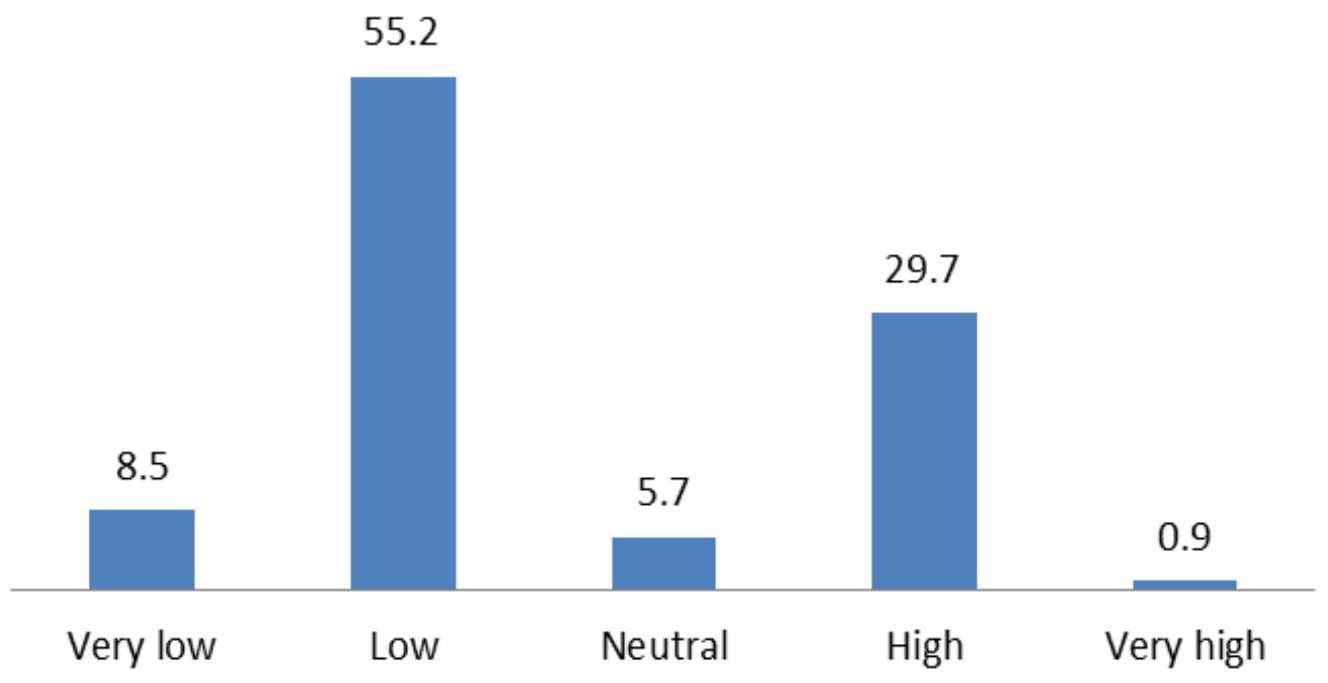

Figure 4. Frequency analysis for Question 10.

Road conditions vary according to the type of street and they significantly impact the whole body vibration among bus drivers. In conclusion, bus drivers use the roads that are in good condition. Most of the respondents were express bus drivers that use the freeways. So, the vibration levels to which the bus drivers are exposed are low. With higher exposure to WBV, performance deteriorates [24]. 


\section{CONCLUSIONS}

From the findings of the study, it is recommended that, in order to mitigate the inadequacy of driving materials, management needs to increase the awareness of the bus drivers of the factors that may lead to the lack of performance. Further studies involving others factors should be undertaken to increase the resources in their support. It is also hoped that this finding will help to increase awareness among bus drivers so that their performance is increased so leading to fewer accidents.

\section{ACKNOWLEDGMENTS}

The authors would like to thanks to Universiti Malaysia Kelantan for financial supports and laboratory facilities

\section{REFERENCES}

[1] Malaysia population clock Department of Statistics Malaysia; 2015.

[2] Cengiz TG. A field study on driversâ thermal comfort with road trials. Gazi University Journal of Science. 2009;22:301-11.

[3] Parsons K. Environmental ergonomics: a review of principles, methods and models. Applied Ergonomics. 2000;31:581-94.

[4] Fisk WJ. Health and productivity gains from better indoor environments and their relationship with building energy efficiency. Annual Review of Energy and the Environment. 2000;25:537-66.

[5] Alahmer AO, M.A Mayyas, A and Dongri, S. Effect of relative humidity and temperature control on in-cabin thermal comfort state: Thermodynamic and psychometric analyses. Applied Thermal Engineering. 2011;31:2636-44.

[6] Ismail AB, RA Jusoh, N Makhtar, NK Rahman and MNA Meier, C. Assessment of thermal comfort at Malaysian automobile industry. Asian International Journal of Science and Technology in Production and Manufacturing Engineering. 2010;3:73-88.

[7] Mukherjee AK, Bhattacharya, S. K Ahmed, S Roy, S. K Roychowdhury and Sen, S. Exposure of drivers and conductors to noise, heat, dust and volatile organic compounds in the state transport special buses of Kolkata city. Transportation Research Part D: Transport and Environment. 2003;8:11-9.

[8] Shaharon MNaJ, J. Thermal comfort assessment-a study toward workersâ€тM satisfaction in a low energy office building. American Journal of Applied Sciences. 2012;9:1037.

[9] Musat RaH, E. Parameters and models of the vehicle thermal comfort. Acta Universitatis Sapientiae, Electrical and Mechanical Engineering. 2009;1:215-26.

[10] Blood RPP, J. D. Yost, M. G. Ching, R. P and Johnson, P. W. Whole body vibration exposures in metropolitan bus drivers: a comparison of three seats. Journal of Sound and Vibration. 2010;329:109-20.

[11] Thamsuwan O, Blood, R. P, Ching, R. P, Boyle, L and Johnson, P. W. Whole body vibration exposures in bus drivers: a comparison between a high-floor coach and a low-floor city bus. International Journal of Industrial Ergonomics. 2013;43:9-17. 
[12] Charles KE, Reardon, J. T and Magee, R.J. Indoor air quality and thermal comfort in open-plan offices: Institute for Research in Construction, National Research Council of Canada; 2005.

[13] Gameiro da Silva MC. Measurements of comfort in vehicles. Measurement Science \&Technology. 2002;13:801-20.

[14] Krejcie R, Morgan DW. Determining sample size for research activities. Educational and Psychological Measurement.1970; 30(3): 607-10.

[15] Spagnolo JDD, and Richard A field study of thermal comfort in outdoor and semi-outdoor environments in subtropical Sydney Australia. Building and Environment. 2003;38:721-38.

[16] Shek KWaC, W.T. Combined comfort model of thermal comfort and air quality on buses in Hong Kong. Science of the Total Environment. 2008;389:277-82.

[17] Zhang H, Wu Q, Lin J, Chen J, Xu Z. Thermal conductivity of polyethylene glycol nanofluids containing carbon coated metal nanoparticles. Journal of Applied Physics. 2010;108:124304-9.

[18] Hair JFM, Arthur H.S , Philip P. M. Research methods for business. Education+ Training. 2007;49:336-7.

[19] Clements CD. Creating the productive workplace: Taylor \& Francis; 2006.

[20] Wyon DP. Healthy buildings and their impact on productivity. Proceedings of Indoor Air. 1993;93:3-13.

[21] Hussein IRaH, M. A. Field study on thermal comfort in Malaysia. European Journal of Scientific Research. 2009;37:127-45.

[22] Attwood DAD, Joseph M Danz-Reece, Mary E. Ergonomic solutions for the process industries: Gulf Professional Publishing; 2004.

[23] Srivajana W. Effects of air velocity on thermal comfort in hot and humid climates. Thammasat International Journal of Science and Technology. 2003;8:45-54.

[24] McLeod RWaG, M. J. Review of the effects of translational whole-body vibration on continuous manual control performance. Journal of Sound and Vibration. 1989;133:55-115. 